Research paper

\title{
Time-based failure analysis of compressed riverbank riprap
}

MONA JAFARNEJAD, Research Assistant, Laboratory of Hydraulic Constructions (LCH), École Polytechnique Fédérale de Lausanne (EPFL), Lausanne, Switzerland

Email: mona.jafarnejad@epfl.ch (author for correspondence)

MÁRIO J. FRANCA (IAHR Member), Research and Teaching Associate, Laboratory of Hydraulic Constructions (LCH), École Polytechnique Fédérale de Lausanne (EPFL), Lausanne, Switzerland

Email: mario.franca@epfl.ch

MICHAEL PFISTER (IAHR Member), Research and Teaching Associate, Laboratory of Hydraulic Constructions (LCH), École Polytechnique Fédérale de Lausanne (EPFL), Lausanne, Switzerland; Professor, Civil Engineering Department, Haute Ecole d'Ingénierie et d'Architecture (HEIA-FR, HES-SO), 1705 Fribourg, Switzerland

Email: michael.pfister@hefr.ch

ANTON J. SCHLEISS (IAHR Member), Professor, Laboratory of Hydraulic Constructions (LCH), École Polytechnique Fédérale de Lausanne (EPFL), Lausanne, Switzerland

Email: anton.schleiss@epfl.ch

\begin{abstract}
Methods to design riprap-lined channels usually refer to dumped material. Large blocks placed individually by machinery are used when more stability is required. They offer additional resistance against flow erosion since space between blocks is minimized and interlocking increased. The behaviour of this protection has rarely been studied. An experimental investigation was carried out on the stability of compressed riprap as riverbank protection. Riprap was reproduced by uniform crushed limestones with three block sizes. Tests were conducted for three channel slopes under supercritical flow conditions and for constant bank slope. A time-based analysis allowed establishing relations among time to failure, friction velocity, and dimensionless bed shear stress. The results of 45 tests confirm that the rate of block erosion is significantly reduced with increase in the riprap diameter. The time to failure of the riprap protection depends strongly on the longitudinal slope and on the block sizes. An empirical prediction to estimate the riprap time to failure is shown.
\end{abstract}

Keywords: Bank erosion; bank protection; failure; riprap; time-dependent analysis

\section{Introduction}

Riprap is the most widely applied engineering revetment used to protect river banks because it is flexible, long lasting, easily constructed and natural in appearance (Schleiss, 1998). The stability of riprap is mainly determined by a combination of the submerged weight and the interlocking forces between adjacent blocks. Several equations were developed to predict the riprap stability if exposed to the flow considering the block size, the gradation and the thickness, as well as the characteristics of an underlying filter below the blocks (Escarameia \& May,
1992; Maynord, Ruff, \& Abt, 1989; Stevens, Simons, \& Lewis, 1976).

There are two main approaches to designing riprap (Recking \& Pitlick, 2013): one, based on Shields equations, considering tractive forces (bed shear stress), and the other based on Isbash equations, defining a permissible velocity. Both approaches predict the behaviour of blocks being exposed to turbulent flow, using either critical bed shear stress or critical velocity, and have been referenced extensively despite differences in the experimental methods used to derive these thresholds. Shields extrapolated bedload transport rates to a zero

Received 21 June 2015; accepted 10 July 2016/Open for discussion until 31 October 2017. 
value, while Isbash measured the stability of blocks dropped into the flow (Maynord \& Neill, 2008; Maynord et al., 1989).

Stevens et al. (1976) introduced a method based on a safety factor related to the stability of individual blocks in the riprap. They assumed that one block is stable if the various forces causing a possible displacement are below the reaction force resulting from the submerged weight. Wittler and Abt (1988) completed the study of Stevens et al. (1976), adding frictional and contact forces from adjacent blocks. Froehlich and Benson (1996) worked on different angles of repose in order to show the role of the bank slope effect on riprap stability. They used the "particle angle of initial yield" concept which was introduced earlier by Straub (1953) and Grace, Calhoun, and Brown (1973). Brown and Clyde (1989) used the Manning-Strickler equation combined with the Shields relation to develop an equation for sizing stable blocks.

Escarameia and May (1992) presented an equation for the design of riverbank ripraps and gabion mattresses. Stability of dumped riprap was studied by Froehlich (2013) regarding the protection of banks from erosive forces. This evaluation was based on the ratio of static moments resisting and provoking overturning. This ratio results in a safety factor of block overturning that indicates the potential for riprap failure. Stevens, Simons, and Richardson (1984) and Ulrich (1987) considered the submerged weight of the blocks as the only resisting force. Froehlich (2011) distinguished the gravitational force from the buoyant force to calculate the resisting moments and the moments promoting overturning of a single particle, which provides a consistent safety factor. Gravitational and buoyant forces can both promote and resist overturning, depending on the channel bed and bank slopes, and the water-surface slope. Abt, Thornton, Gallegos, and Ullmann (2008) studied the effect of round-shaped riprap stability subjected to overtopping flow. Probabilistic procedures for the design of riverbank riprap were developed by Li, Simons, Blinco, and Samad (1976), PIANC (1987), and later by Froehlich and Benson (1996). They describe the combination of different mechanisms including the persistence of hydrodynamic actions, which represents one of the advantages of these methods in the risk-based design procedure.

Several manuals give guidelines for the general application of dumped block riprap. The US Army Corps of Engineers manual (USACE, 1994) suggested a method for riprap design in channels and rivers based on different coefficients concerning vertical velocity distribution, incipient failure, and riprap thickness. This method was mostly based on Maynord's formula proposed in 1989 (Maynord et al., 1989).

Most of these design methods are limited to dumped and medium size blocks. The incipient motion of particles is used as a failure criterion (De Almeida \& Martin-Vide, 2009) and block movement is assumed to begin only when the upper part of the riprap becomes partly exposed (Townson, 1988). However, if large and heavy blocks are required for stability reasons, they have to be placed individually by machines because of their weight. Consequently, for such a construction technique, the design method used for a dumped riprap becomes conservative.

Riprap failure occurs through different mechanisms. According to Blodgett and McConaughy (1986a, 1986b), and Lagasse, Clopper, Zevenbergen, and Ruff (2006), riprap failure modes are identified as: (1) direct block erosion; (2) translational slide; (3) slump failure; and (4) side-slope failure being often similar to riprap apron failure (Simarro, Civeira, \& Cardoso, 2012). Direct block erosion initiated by flowing water is the most common mechanism. Most riprap design methods were developed based on the failure criterion that considers the first movement of an individual block. Some other authors, such as Maynord et al. (1989), proposed the exposure of the filter underneath the riprap to the flow as failure criteria. This may cause another mechanism, translational slide or slump, in the presence of multi layered riprap (Jafarnejad, 2016; Jafarnejad, Pfister, \& Schleiss, 2012; Jafarnejad, Franca, Pfister, \& Schleiss, 2014).

In the present study, the temporal evolution of the riprap failure with well-positioned blocks was investigated. Particular attention was given to the influence of time during which blocks remain stable. One approach to consider the time is to treat riprap behaviour as a transport problem by defining maximum allowable transport rates. This approach is acceptable if multiple layers of material are considered (Maynord \& Neill, 2008). If riprap is built with one single layer, the use of this approach may be questionable.

Riprap protections constructed with large and compressed blocks placed individually by machines are not considered to fail when only a single block erodes. Failure happens if a group of blocks slides and provokes instability of the river banks. In the present study, the total collapse of all blocks in a section over the whole bank is considered as a failure, thus the failure mechanism considered herein is sliding. This failure type is due to the slumping or sliding of riprap from the top to the toe of the bank, causing full exposure of the filter to the flowing water. This causes bank instability and consequently a downstream or upstream continuation of the riprap failure and a collapse of the bank.

\section{Experimental procedures}

The goal of this research was to characterize the resistance of a river bank riprap, consisting of individually placed and compressed large blocks, subjected to hydrodynamic forces. By varying the block size and streamwise channel slope, 45 experiments were conducted to analyse the effect of the block size of the riprap on its stability. The laboratory tests were carried out on a straight $10 \mathrm{~m}$ long, $1 \mathrm{~m}$ wide (experiments were made with the full width of the channel and with a reduced width of $0.7 \mathrm{~m}$ ) and $0.5 \mathrm{~m}$ deep tilting flume with a trapezoidal section at the Laboratory of Hydraulics Constructions of École Polytechnique Fédérale de Lausanne. The channel was supplied with water from the internal closed circuit system that allowed 
a maximum discharge of $7501 \mathrm{~s}^{-1}$. Discharge was measured by a magnetic inductive flow meter with an accuracy of $\pm 21 \mathrm{~s}^{-1}$ at full span. The set-up of the flume is shown in Fig. 1.

The longitudinal slope of the flume was set to $S=1.5 \%, 3 \%$ and $5.5 \%$. The transversal riprap bank slope was fixed at $0.7 \mathrm{~V}$ $1 \mathrm{H}$ (V: Vertical and H: Horizontal) $\left(35^{\circ}\right)$. The riprap blocks consisted of uniform crushed limestone, with a specific density of $S_{B}=2.65$. Three different equivalent average block sizes of $D=0.037,0.042$ and $0.047 \mathrm{~m}$ were tested individually and the grain size distribution of the blocks is considered uniform as shown by the uniformity parameter $\sigma$ in Table 1 . Wittler and Abt (1988) reported that a riprap with a uniform gradation (when expecting similar $D$ ) tends to be globally more stable, as compared to wide distribution of block sizes. The blocks were thus uniformly selected and applied in the experiments. Froehlich (2011) conducted tests with various block sizes (including those used herein), considering crushed material. The angle of repose of blocks can be assumed as based on Froehlich's experiments (Froehlich, 2011).

The riprap blocks were placed individually in a packed arrangement with the lowest possible space between them over the sediments with a wide grain size distribution that simulate a bank filter. The riprap was subjected to compression by means of a plain plate to bring the void space to a minimum. To simulate naturally hydraulic rough flow conditions, the channel bed

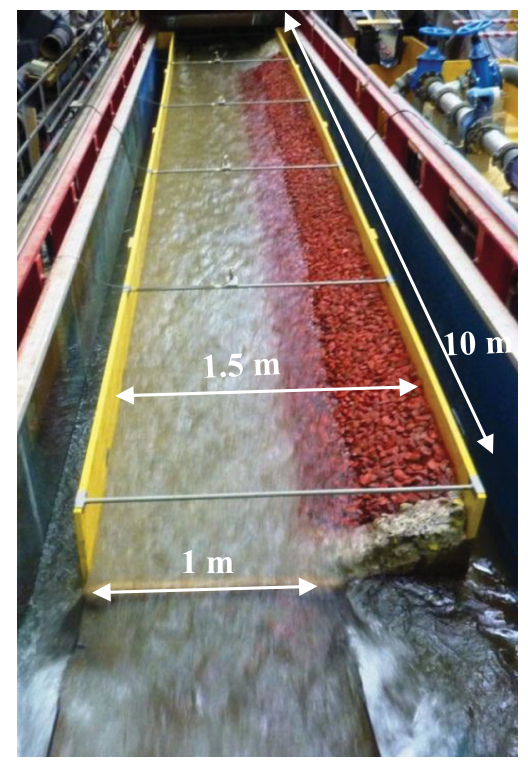

Figure 1 Photo of the experimental flume, streamwise view

Table 1 Grain size distribution and respective uniformity index $\sigma$ of the riprap blocks

\begin{tabular}{lccccccc}
\hline Group & $\begin{array}{c}D_{15} \\
(\mathrm{~mm})\end{array}$ & $\begin{array}{c}D_{30} \\
(\mathrm{~mm})\end{array}$ & $\begin{array}{c}D_{50} \\
(\mathrm{~mm})\end{array}$ & $\begin{array}{c}D_{65} \\
(\mathrm{~mm})\end{array}$ & $\begin{array}{c}D_{85} \\
(\mathrm{~mm})\end{array}$ & $\begin{array}{c}D_{\max } \\
(\mathrm{mm})\end{array}$ & $\begin{array}{c}\sigma=D_{85} / \\
D_{15}(-)\end{array}$ \\
\hline I & 33 & 35 & 37 & 38 & 39 & 40 & 1.18 \\
II & 41 & 41.5 & 42 & 43 & 44 & 45 & 1.07 \\
III & 46 & 46.5 & 47 & 48 & 49 & 50 & 1.06 \\
\hline
\end{tabular}

Table 2 Characteristics of the sediments which form the bank filter underneath the riprap and which are glued to the channel bed to form a rough bed ( $D_{m}$ is the mean diameter and corresponds to $\left.D_{65}\right)$

\begin{tabular}{lcccccc}
\hline $\begin{array}{l}D_{10} \\
(\mathrm{~mm})\end{array}$ & $\begin{array}{c}D_{35} \\
(\mathrm{~mm})\end{array}$ & $\begin{array}{c}D_{50} \\
(\mathrm{~mm})\end{array}$ & $\begin{array}{c}D_{m}=D_{65} \\
(\mathrm{~mm})\end{array}$ & $\begin{array}{c}D_{75} \\
(\mathrm{~mm})\end{array}$ & $\begin{array}{c}D_{90} \\
(\mathrm{~mm})\end{array}$ & $\begin{array}{c}D_{\max } \\
(\mathrm{mm})\end{array}$ \\
\hline 3.2 & 4.4 & 5.3 & 8.5 & 9.1 & 14.8 & 32 \\
\hline
\end{tabular}

was roughened by gluing the same sediments used for the filter (Table 2).

The distinction between dumped and compressed ripraps was observed by means of porosity measurements. Porosity tests were performed to obtain the different void volumes in dumped and compressed riprap. Table 3 shows the porosity $\left(n_{p}\right)$ resulting from these tests per block size and construction type. When compressed, the porosity is reduced by $2 \%$ for $D=0.037 \mathrm{~m}$, by $5 \%$ for $D=0.042 \mathrm{~m}$, and by $10 \%$ for $D=0.047 \mathrm{~m}$, if compared to dumped riprap. Remarkably, with the compression, the relation of the porosity between the different sizes is inversed (Table 3). This is related to the shape of the blocks which, when the size is smaller, tends to be more spherical. The more spherical shape thus allows less void space in dumped conditions, which is closer to the maximum porosity achieved if in compacted conditions. The compression is thus more effective for larger block sizes and, if these are individually placed, may have a lower porosity than smaller grain sizes. The interlocking forces increase as the void volume between blocks reduces since the blocks have a closer arrangement. The porosity of the riprap in the experiments by Maynord (Maynord et al., 1989) was $44-46 \%$, with limestone blocks of $D=0.025 \mathrm{~m}$ and $0.051 \mathrm{~m}$, similar to the present blocks if dumped.

The variables relevant to the time evolution of riprap failure subjected to flow include those related to the water properties (viscosity and density, $\rho$ ), the riprap (mean diameter, $D$, grain size distribution and density, $\rho_{s}$ ), the flow (water depth, $h$, a flow velocity, $V$, gravity acceleration, $g$, and bed shear stress, $\tau$ ), the channel geometry (longitudinal slope, $S$, bank slope, $\alpha$, and channel width, $W$ ) and the time (time to failure, $t_{f}$ ) (Yalin, 1977).

Under the tested conditions, the flow is turbulent, thus the effect of the fluid viscosity can be neglected (Froude similarity). The riprap block size distribution is uniform, so the grain size distribution is also not considered. Hence, the remaining intervening variables are $D, h, S, \alpha$, and $W$ as geometric variables;

Table 3 Porosity $\left(n_{\mathrm{p}}\right)$ of dumped and compressed riprap with three different sizes of blocks (the values shown are the results of four replicable tests)

\begin{tabular}{lcc}
\hline$D(\mathrm{~mm})$ & Dumped $n_{p}(\%)$ & Compressed $n_{p}(\%)$ \\
\hline 37 & $43.71 \pm 0.83$ & $41.52 \pm 0.49$ \\
42 & $44.73 \pm 0.41$ & $40.78 \pm 0.89$ \\
47 & $46.56 \pm 0.59$ & $36.80 \pm 0.21$ \\
\hline
\end{tabular}


$V, g$, and $t_{f}$ as kinematic variables and $\rho, \rho_{s}$, and $\tau$ as dynamic variables. Two velocity scales may be considered, depending on whether the flow or the erosion of the riprap blocks is under analysis; cross-section averaged velocity is used to define the flow regime (based on Froude number) whereas the friction velocity is considered a more appropriate scale for the action of the flow upon the blocks.

The dimensionally independent variables used for the definition of normalized parameters are $D, g$ and $\rho_{s}$ (or $\rho S_{B}$, where $S_{B}$ is the riprap relative density). Alternatively, $h$ may be used as geometric variable, as discussed below.

Based on preliminary tests and typical flood peak durations in mountain rivers, the maximum duration of the experiments was set to $180 \mathrm{~min}$. The corresponding prototype time is important for the analysis of the results since it represents the expected duration of the flood peak assuming a constant mean discharge, which may cause the riprap failure. The time scale based on the Froude similarity is given as:

$$
\lambda_{t}=\frac{t_{p}}{t_{m}}=\sqrt{\frac{L_{p}}{L_{m}}}
$$

where $t$ represents time, $L$ represents length, and subscripts $p$ and $m$ stand for prototype and model, respectively. A geometrical scale for typical alpine mountain rivers is $L_{p} / L_{m}=25$ which results in a time scale of 5 . Tests lasting $180 \mathrm{~min}$ are thus roughly equivalent to prototype flood peak durations of $15 \mathrm{~h}$, which is representative of typical observed flood durations in mountainous rivers. Given this scale, the size of our blocks are in the range of $1-1.2 \mathrm{~m}$ in prototype, which is the size of blocks typically used in alpine rivers.

The experimental programme was defined in order to identify the time to failure and the unit discharge causing failure. Lower discharges could cause direct block erosion during the tests but do not lead to full failure of the riprap as above defined. For the fixed channel slopes, supercritical flow conditions $(1.09<\mathrm{F}<1.89$, where $\mathrm{F}$ is the Froude number defined as $\left.\mathrm{F}=v_{m} /(g h)^{0.5}\right)$ occurred for all discharges. The discharge was increased subsequently (for subsequent tests) until failure occurred, providing the failure discharge (Table 4). Flow depths were measured along the channel axis by means of ultrasonic probes $( \pm 0.5 \mathrm{~mm})$ with an acquisition frequency of $100 \mathrm{~Hz}$, at four different positions located at 4, 6 and $8 \mathrm{~m}$ downstream the entrance of the channel. The measurements were made for durations long enough to assure the stability of the average value. The first $6 \mathrm{~m}$ of the riprap from upstream was fixed using mortar keeping, however, the same roughness, to avoid an influence of the model inlet.

The riprap erosion rate was measured with a one-minute frequency by tracking and counting the number of eroded blocks, observed by three cameras. Furthermore, the eroded blocks were collected and weighed in a sediment trap at the downstream channel end in order to validate the total erosion measurements. Single blocks that eroded during the start of the tests
( $<2 \mathrm{~min}$ ) were not considered for the calculation of the erosion rate. Moreover, the results are confined to the flume reach between $6.5 \mathrm{~m}$ and $9.5 \mathrm{~m}$, where constant flow depth (roughly uniform flow) occurred. The water surface slope taken from the water level measurements was compared with the channel longitudinal slope. The differences between these two values were on average $\pm 2.5 \%$ of the channel bed slope, with a maximum of $10 \%$ for the lowest slope and the highest discharge tested. Blocks being eroded outside of that zone were excluded. All tests had the same initial conditions. After each test, independently of whether or not there was failure, all the blocks were removed and the slope prepared again under the same conditions for the next test.

The detailed parameters of the experiments are shown in Table 4. Experiments were divided into three groups, I to III, each group including a different block size $(D=0.037,0.042$ and $0.047 \mathrm{~m}$ ). The riprap consisted of one single layer, and its thickness is accordingly $D$. Tests were run until total failure occurred, or for a maximum duration of $180 \mathrm{~min}$. Figure 2 shows the set-up before and after three different tests. Eroded parts of the riprap and the failed area after the experiment are shown in Fig. 2b. In this figure direct block erosion is visible along the toe of the riprap. At the model end, total riprap failure over the entire bank height is visible.

\section{Results and discussion}

For each group of riprap block sizes, several unit discharges were tested. Some of them initiated failure, while for others no failure occurred during the maximum test duration of $180 \mathrm{~min}$. Protection for the channel bank was materialized with one layer of riprap blocks, which corresponds to the thickness typically used in alpine rivers.

Table 4 summarizes the hydraulic parameters of all 45 tests for the three different channel slopes, including the width of the channel $(W)$, unit discharge $(q)$, water depth $(h)$, size of the blocks $(D)$, cross-section averaged flow velocity $\left(v_{m}\right)$, Froude number $(F)$ and bed shear stress $(\tau)$ estimated considering uniform flow conditions. The time to failure $\left(t_{f}\right)$ and the riprap condition after the test (failed $=$ Yes; remained stable $=$ No) are given as well.

Three examples of tests with $S=3 \%$ for all different block sizes are shown in Fig. 2 (tests 5, 10 and 17). During test 5, with the smallest $D=0.0375 \mathrm{~m}$ and $q=0.262 \mathrm{~m}^{2} \mathrm{~s}^{-1}$, direct block erosion started right after starting the test. The total bank failure occurred after $94 \mathrm{~min}$. For the test 10, with $D=0.042 \mathrm{~m}$ and $q=0.421 \mathrm{~m}^{2} \mathrm{~s}^{-1}$, the total failure occurred after $121 \mathrm{~min}$. For the test 17 , with $D=0.047 \mathrm{~m}$ and $q=0.480 \mathrm{~m}^{2} \mathrm{~s}^{-1}$, the total failure occurred after $160 \mathrm{~min}$. A significant erosion at the toe of the riprap protection is observed in this case. It can be observed that the filter was fully exposed over the bank height in the failed sections, whereas the riprap remained stable further upstream and downstream. 
The time evolution of the cumulated number of eroded blocks for the three groups of experiments, and a longitudinal slope of $S=3 \%$, is shown in Fig. $3 \mathrm{a}-\mathrm{c}$. The total failure of a riprap is indicated by an abrupt rise of the cumulative curve (inclination $\approx \infty$ ) corresponding to a sudden increase of the eroded block number. Figure 3 a shows the tests including the smallest blocks (group I) for six different unit discharges. It is observed, as expected, that the time to failure increases when the discharge decreases. Two of the tests in this group had a total failure with a failure discharge for this block size between $q=0.249 \mathrm{~m}^{2} \mathrm{~s}^{-1}$ and $0.262 \mathrm{~m}^{2} \mathrm{~s}^{-1}$. The complete failure occurred after 94 and $62 \min$ for $q=0.262 \mathrm{~m}^{2} \mathrm{~s}^{-1}$ and $q=0.301 \mathrm{~m}^{2} \mathrm{~s}^{-1}$, respectively. For medium size blocks (group II) the data from seven different tests are given in Fig. 3 b. The significant influence of increasing discharge on the time to total failure and in the number of eroded blocks is evident. The first complete failure was observed for $q=0.407 \mathrm{~m}^{2} \mathrm{~s}^{-1}$ after $162 \mathrm{~min}$. By increasing the unit discharge, complete

Table 4 Characteristics and main results of the tests with three different longitudinal slopes

\begin{tabular}{|c|c|c|c|c|c|c|c|c|c|c|c|}
\hline Test & Channel slope & Group & $D(\mathrm{~m})$ & $W(\mathrm{~m})$ & $Q\left(\mathrm{~m}^{2} \mathrm{~s}^{-1}\right)$ & $h(\mathrm{~m})$ & $v_{m}\left(\mathrm{~m} \mathrm{~s}^{-1}\right)$ & $F(-)$ & $\tau(\mathrm{Pa})$ & $t_{f}(\min )$ & Failure (-) \\
\hline 1 & $3 \%$ & I & 0.037 & 1.00 & 0.166 & 0.121 & 1.59 & 1.46 & 35.61 & - & No \\
\hline 2 & & & & 1.00 & 0.208 & 0.131 & 1.84 & 1.62 & 38.55 & - & No \\
\hline 3 & & & & 1.00 & 0.242 & 0.143 & 1.97 & 1.66 & 42.08 & - & No \\
\hline 4 & & & & 1.00 & 0.249 & 0.145 & 1.99 & 1.67 & 42.67 & - & No \\
\hline 5 & & & & 1.00 & 0.262 & 0.150 & 2.03 & 1.67 & 44.15 & 94 & Yes \\
\hline 6 & & & & 1.00 & 0.301 & 0.165 & 2.13 & 1.67 & 48.56 & 62 & Yes \\
\hline 7 & & II & 0.042 & 1.00 & 0.348 & 0.167 & 2.27 & 1.78 & 49.15 & - & No \\
\hline 8 & & & & 0.70 & 0.380 & 0.175 & 2.38 & 1.81 & 51.50 & - & No \\
\hline 9 & & & & 0.70 & 0.407 & 0.183 & 2.44 & 1.83 & 53.86 & 162 & Yes \\
\hline 10 & & & & 0.70 & 0.421 & 0.186 & 2.49 & 1.84 & 54.74 & 121 & Yes \\
\hline 11 & & & & 0.70 & 0.430 & 0.188 & 2.52 & 1.85 & 55.33 & 68 & Yes \\
\hline 12 & & & & 0.70 & 0.442 & 0.193 & 2.52 & 1.83 & 56.80 & 14 & Yes \\
\hline 13 & & & & 0.70 & 0.473 & 0.200 & 2.61 & 1.87 & 58.86 & 6 & Yes \\
\hline 14 & & III & 0.047 & 0.70 & 0.432 & 0.188 & 2.53 & 1.85 & 55.92 & - & No \\
\hline 15 & & & & 0.70 & 0.443 & 0.191 & 2.55 & 1.87 & 56.21 & - & No \\
\hline 16 & & & & 0.70 & 0.461 & 0.196 & 2.59 & 1.87 & 57.68 & - & No \\
\hline 17 & & & & 0.70 & 0.480 & 0.210 & 2.65 & 1.89 & 58.86 & 160 & Yes \\
\hline 18 & $1.5 \%$ & I & 0.037 & 0.70 & 0.287 & 0.181 & 1.51 & 1.10 & 21.22 & - & No \\
\hline 19 & & & & 0.70 & 0.303 & 0.197 & 1.54 & 1.11 & 21.43 & 172 & Yes \\
\hline 20 & & & & 0.70 & 0.314 & 0.202 & 1.55 & 1.10 & 21.85 & 87 & Yes \\
\hline 21 & & & & 0.70 & 0.330 & 0.209 & 1.58 & 1.11 & 22.40 & 43 & Yes \\
\hline 22 & & & & 0.70 & 0.346 & 0.215 & 1.61 & 1.11 & 22.94 & 9 & Yes \\
\hline 23 & & II & 0.042 & 0.70 & 0.387 & 0.220 & 1.58 & 1.09 & 23.67 & - & No \\
\hline 24 & & & & 0.70 & 0.402 & 0.239 & 1.68 & 1.10 & 24.88 & 143 & Yes \\
\hline 25 & & & & 0.70 & 0.423 & 0.246 & 1.72 & 1.11 & 25.44 & 123 & Yes \\
\hline 26 & & & & 0.70 & 0.433 & 0.250 & 1.73 & 1.11 & 25.75 & 63 & Yes \\
\hline 27 & & & & 0.70 & 0.458 & 0.259 & 1.77 & 1.11 & 26.45 & 6 & Yes \\
\hline 28 & & III & 0.047 & 0.70 & 0.432 & 0.252 & 1.71 & 1.09 & 25.91 & - & No \\
\hline 29 & & & & 0.70 & 0.452 & 0.259 & 1.75 & 1.10 & 26.45 & 134 & Yes \\
\hline 30 & & & & 0.70 & 0.472 & 0.266 & 1.77 & 1.10 & 26.99 & 95 & Yes \\
\hline 31 & & & & 0.70 & 0.482 & 0.270 & 1.78 & 1.10 & 27.30 & 71 & Yes \\
\hline 32 & $5.5 \%$ & I & 0.037 & 0.70 & 0.202 & 0.100 & 2.39 & 2.03 & 60.13 & - & No \\
\hline 33 & & & & 0.70 & 0.231 & 0.109 & 2.42 & 2.05 & 60.82 & 120 & Yes \\
\hline 34 & & & & 0.70 & 0.255 & 0.117 & 2.46 & 2.04 & 62.89 & 42 & Yes \\
\hline 35 & & & & 0.70 & 0.273 & 0.122 & 2.51 & 2.05 & 63.91 & 4 & Yes \\
\hline 36 & & II & 0.042 & 0.70 & 0.260 & 0.121 & 2.15 & 2.00 & 51.71 & - & No \\
\hline 37 & & & & 0.70 & 0.277 & 0.123 & 2.25 & 2.05 & 53.73 & 151 & Yes \\
\hline 38 & & & & 0.70 & 0.332 & 0.139 & 2.39 & 2.04 & 59.43 & 55 & Yes \\
\hline 39 & & & & 0.70 & 0.355 & 0.145 & 2.45 & 2.05 & 61.51 & 8 & Yes \\
\hline 40 & & & & 0.70 & 0.429 & 0.163 & 2.63 & 2.08 & 67.61 & 2 & Yes \\
\hline 41 & & III & 0.047 & 0.70 & 0.310 & 0.135 & 2.53 & 1.85 & 55.92 & - & No \\
\hline 42 & & & & 0.70 & 0.337 & 0.141 & 2.55 & 1.87 & 57.68 & 135 & Yes \\
\hline 43 & & & & 0.70 & 0.347 & 0.143 & 2.59 & 1.87 & 58.86 & 111 & Yes \\
\hline 44 & & & & 0.70 & 0.367 & 0.149 & 2.65 & 1.89 & 59.71 & 50 & Yes \\
\hline 45 & & & & 0.70 & 0.381 & 0.152 & 2.68 & 1.90 & 59.92 & 5 & Yes \\
\hline
\end{tabular}

Note: $D$, diameter of the blocks; $W$, channel width; $q$, unit discharge $=$ discharge/bed width; $h$, water depth; $v_{m}$, mean velocity $=$ discharge/flow area; F, Froude number $=v_{m} /(g h)^{0.5} ; \tau$, bed shear stress; $t_{f}$, time to total failure. 
failure occurs much earlier. For the largest blocks (group III), the failure condition was reached only for the test with $q=0.480 \mathrm{~m}^{2} \mathrm{~s}^{-1}$. Figure $3 \mathrm{c}$ indicates that larger blocks increase not only the failure discharge but also the time to failure. Thus, for a similar unit discharge, the rate of block erosion reduces if the blocks become larger.

(a)
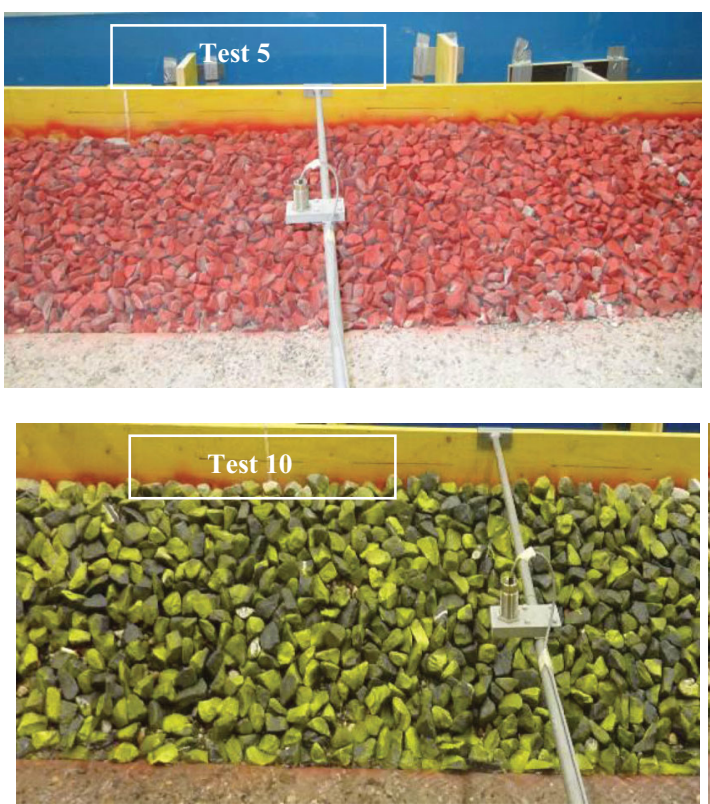

(b)


Figure 2 Riprap (a) before, and (b) after failure for tests 5, 10 and 17 weight of the blocks as:

$$
\tau^{*}=\frac{\tau}{\left(S_{B}-1\right) g \rho D}
$$

The dimensionless bed shear stress represents the balance of hydrodynamic forces acting on the riprap and the submerged 

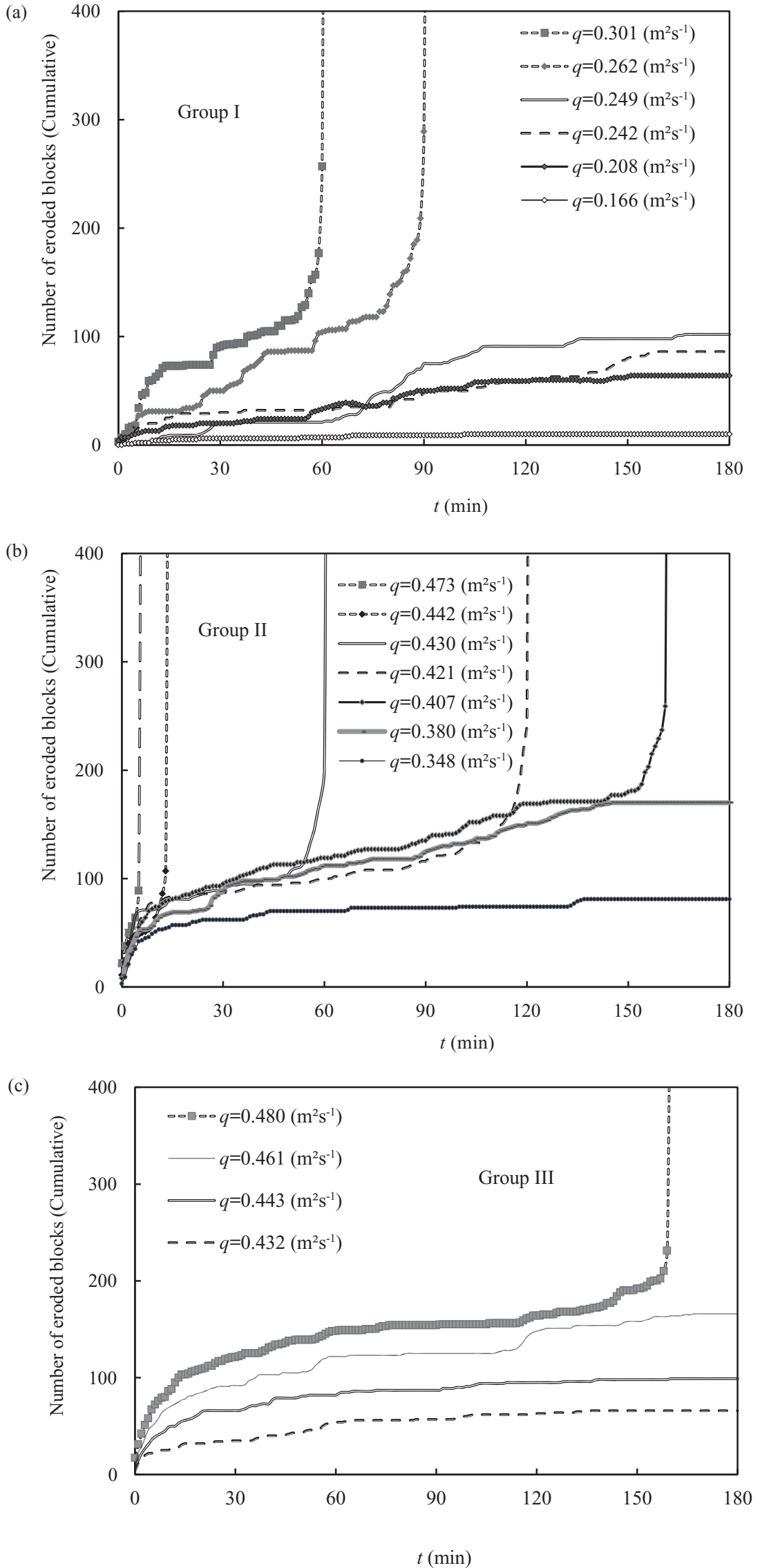

Figure 3 Time evolution of cumulative block erosion rate for different tests for a longitudinal channel slope of $3 \%$ : (a) with $D=0.037 \mathrm{~m}(\mathrm{Group} \mathrm{I})$; (b) with $D=0.042 \mathrm{~m}$ (Group II); and (c) with $D=0.047 \mathrm{~m}$ (Group III) 
The bed shear stress was calculated as:

$$
\tau=\rho g R_{h} S
$$

where $R_{h}$ is the hydraulic radius.

A dimensionless time to failure $T_{D}^{*}$ can be defined with the block size $D$ as normalizing length scale as follows:

$$
T_{D}^{*}=\frac{t_{f} u_{*}}{D}
$$

where the friction velocity $u_{*}$ is:

$$
u_{*}=\sqrt{\frac{\tau}{\rho}}
$$

which is considered as a velocity scale representative of the shear causing erosion and acting on the blocks of size $D$. In order to understand what influences the time to failure, the dimensionless bed shear stress was compared to the dimensionless time to failure $T_{D}^{*}$ (Fig. 4).

It can be seen in Fig. 4a that for a certain channel slope, the relationship between $T_{D}^{*}$ and $\tau^{*}$ is linear with good agreement with coefficients of determination of $R^{2} \approx 0.94,0.83$ and 0.90 , for $S=1.5 \%, 3 \%$, and $5.5 \%$. Nevertheless a small change in $\tau^{*}$ has a pronounced effect on $T_{D}^{*}$, which decreases with increasing slope. For each slope group, the relationship between $T_{D}^{*}$ and $\tau^{*}$ seems linear. Fig. 4 also shows that the inclination of the linear relation between $T_{D}^{*}$ and $\tau^{*}$ changes with $S$. Results confirm, as expected, that a higher bed shear stress is needed to generate the same characteristic time to failure.

Figure $4 \mathrm{~b}$ shows the relation between $T_{D}^{*}$ and the dimensionless bed shear stress multiplied by the term $S^{-0.7}$. The linear regression shown in Fig. $4 \mathrm{~b}$ has $R^{2}=0.60$. In Fig. 5 only the block size $D$ was used as geometric scale to normalize the variables in the description of the time to failure.

The time to failure may alternatively be normalized using the flow depth $h$ as geometric parameter:

$$
T_{h}^{*}=\frac{t_{f} u_{*}}{h}
$$

Valid arguments can be made regarding the use of both scales to normalize the time to failure. The displacement of blocks is made intermittently by large size turbulent coherent structures
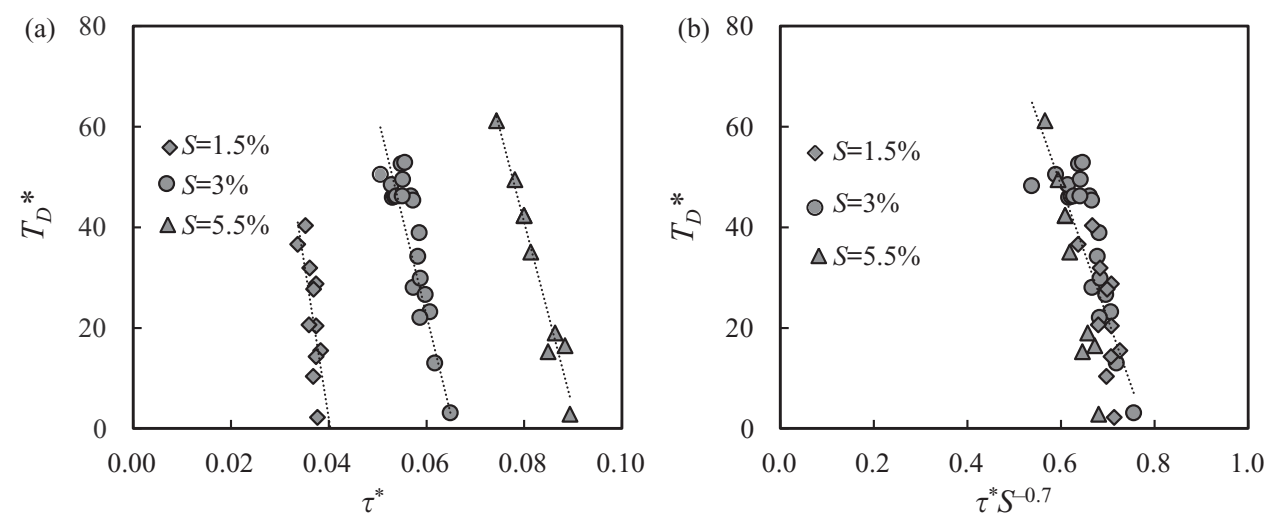

Figure 4 (a) Dimensionless failure time $T_{D}^{*}$ as a function of dimensionless bed shear stress $\tau^{*}$, grouped by slopes $S=1.5 \%, 3 \%$ and $5.5 \%$ for the tests encounter the failure. The dotted lines represent linear regressions made within the same slope. (b) Dimensionless failure time ( $\left.T_{D}^{*}\right)$ as a function of the dimensionless bed shear stress $\left(\tau^{*} S^{-0.7}\right)$. The dotted line corresponds to a linear regression of the data
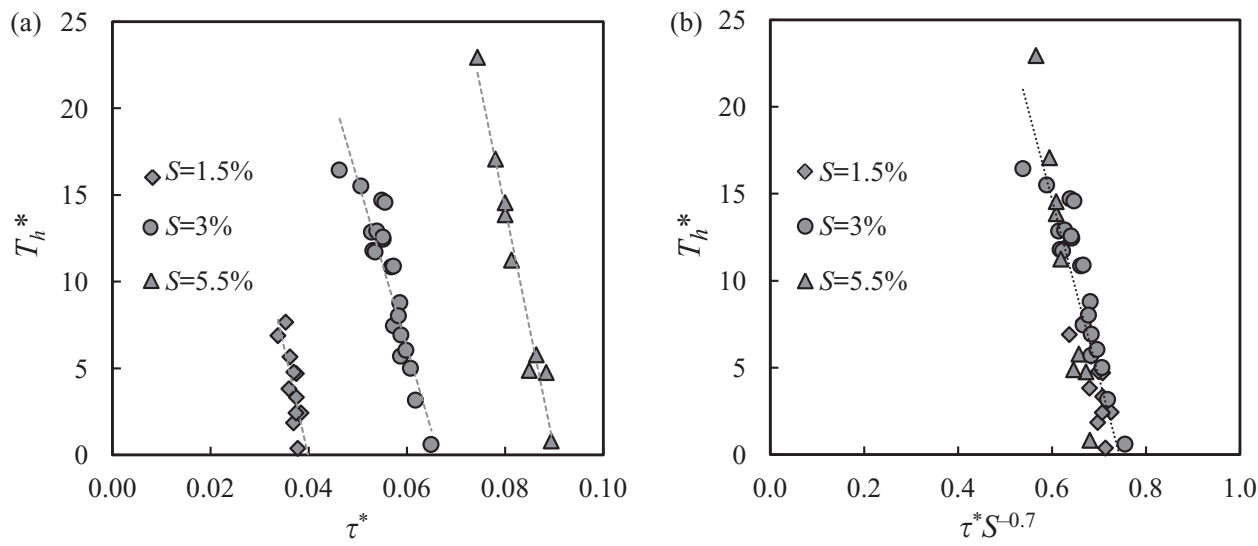

Figure 5 (a) Dimensionless failure time $T_{h}^{*}$ as a function of dimensionless bed shear stress $\tau^{*}$, grouped by slopes $S=1.5 \%, 3 \%$ and $5.5 \%$ for the tests encounter the failure. The dotted lines represent linear regressions made within the same slope. (b) Dimensionless failure time ( $\left.T_{D}^{*}\right)$ as a function of the dimensionless bed shear stress $\left(\tau^{*} S^{-0.7}\right)$. The dotted line corresponds to a linear regression of the data 

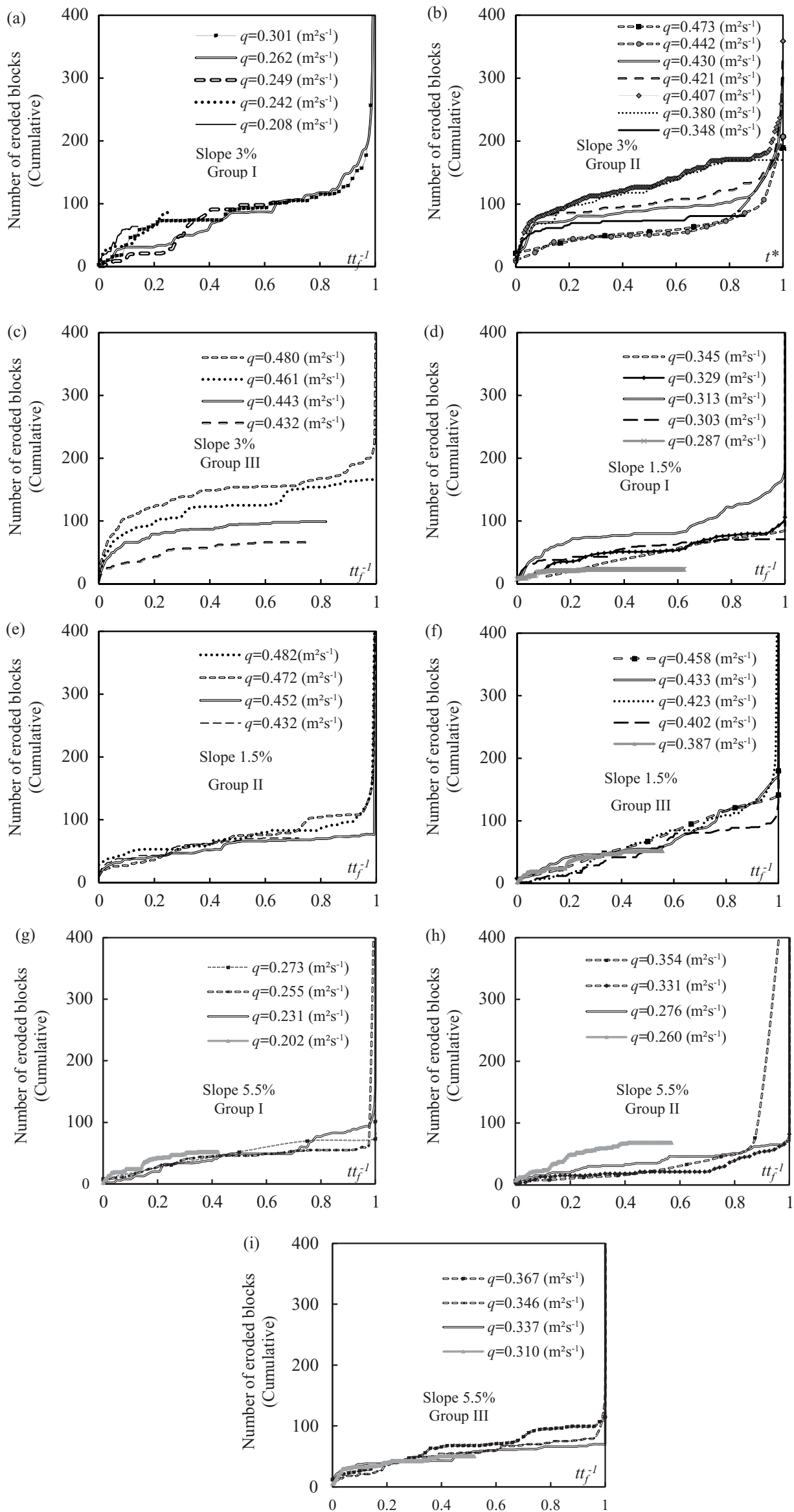

Figure 6 (a) Dimensionless failure time $T_{h}^{*}$ as a function of dimensionless bed shear stress $\tau^{*}$, grouped by slopes $S=1.5 \%, 3 \%$ and $5.5 \%$ for the tests encounter the failure. The dotted lines represent linear regressions made within the same slope. (b) Dimensionless failure time ( $\left.T_{D}^{*}\right)$ as a function of the dimensionless bed shear stress $\left(\tau^{*} S^{-0.7}\right)$. The dotted line corresponds to a linear regression of the data 
that scale at most with the flow depth $h$. These largest structures correspond to the most energetic in the flow. However, the most effective turbulent structures to the blocks displacement should scale with the block itself, with $D$.

Figure 5a shows the dimensionless time to failure $T_{h}^{*}$ again as a function of $\tau^{*}$ for the three tested longitudinal slopes. There is still a good agreement for a linear relationship between $T_{h}^{*}$ and $\tau^{*}\left(R^{2} \approx 0.85,0.83\right.$ and 0.96 for $S=1.5 \%, 3 \%$ and $5.5 \%$, respectively). Figure $5 \mathrm{~b}$ shows again that the time to failure normalized with $h$ presents a good collapse as a function of the dimensionless bed shear stress multiplied by $S^{-0.7}$. Compared to the approach with $T_{D}^{*}$, this results in a better determination with $R^{2}=0.78$ which indicates a stronger influence of the flow depth.

The time to failure $\left(t_{f}\right)$ for tests which remained stable during the three hours can now be predicted based on Fig. $5 \mathrm{~b}$ and on the parameters defined in Eqs (2) and (6). Both Figs 4a and 5b indicate that the dimensionless bed shear stress needed to dislodge the riprap rock on the bank increases as the longitudinal bed slope increases. This may be due to an increase of the overall resisting moments of the blocks due to an increase of the supporting points. When the longitudinal slope of the channel increases, the blocks become more interlocked and supplementary supporting points exist upstream of each individual rock.

In Fig. 6, the cumulative number of the eroded blocks is shown as a function of the time normalized by the time to failure $t_{f}$, observed or estimated empirically from Fig. 5b, if no failure was observed. This figure illustrates the similitude of the evolution of the block erosion for several tests with the same slope.

In the experiments where failure occurred, the number of eroded blocks presents an asymptote for $t / t_{f}=1$. In the stable experiments, data on the number of eroded blocks stop within the time range of $0<t / t_{f}<1$. For these experiments, the unit discharge is below the value necessary for the occurrence of failure. The range of block erosion shows that the number of eroded blocks is not increased drastically comparing to the predicted normalized time to failure. This means that the cumulative block erosion remains limited until failure occurs, independent of the block size.

The block erosion for the different experiments in Fig. 6 shows a similar pattern. An approximated model for the block erosion, bounded by the beginning of the hydrodynamic action and the failure of the riprap, may be established based on Fig. 6 . A higher erosion rate occurs in the beginning of the experiment. Thereafter, the rate of erosion becomes roughly constant until near the failure time. The amount of eroded blocks just before the time to failure increases asymptotically.

In Fig. $6 \mathrm{a}-\mathrm{c}$, the normalized time to failure is shown for $S=3 \%$ for three different block sizes. The cumulative number of eroded blocks for $t / t_{f}<0.9$ is less than 200 for all block sizes. It can be seen that lower block sizes face failure for lower unit discharges. Figure $6 \mathrm{~d}-\mathrm{f}$ show the normalized time to failure for the three different block sizes and for $S=0.5 \%$. The cumulative number of eroded blocks for $t / t_{f}<0.9$ is always less than 150 . Figure $6 \mathrm{~g}-\mathrm{i}$ show the normalized time to failure for $S=5.5 \%$ also for three different block sizes. The cumulative number of eroded blocks for $t / t_{f}<0.9$ is less than 100 . The limits in the rate of erosion are higher for $S=3 \%$ as compared to the other slopes. It should be noted that the unit discharge in each group of tests had to be increased as the block sizes are larger to provoke failure.

\section{Conclusions}

The stability of compressed, well-positioned riverbank riprap consisting of one single layer was experimentally analysed herein, considering the influence of the block sizes, the specific discharge and the river bed slope on the time to failure. Particular attention was given to the time to failure defined as the duration until the riprap collapsed totally after starting the experiments. The experiments included three different longitudinal channel slopes of $1.5 \%, 3 \%$ and $5.5 \%$ and a constant embankment slope of $0.7 \mathrm{~V}-1 \mathrm{H}$. The block diameters varied from $0.037 \mathrm{~m}$ to $0.047 \mathrm{~m}$. A maximum test duration of three hours was established to cover roughly a $15 \mathrm{~h}$ flood duration when taking into account a typical scale factor.

Classical stability criteria consider failure as the instant when direct erosion of the first riprap block occurs. A time-dependent analysis of the riprap failure is herein presented where the failure corresponds to the complete sliding of an entire riprap section. Thus, the present analysis regards sliding as the failure mechanism instead of direct block erosion. This failure mechanism is linked to the time to which the riprap protection is subjected to a high flow.

The results of this study showed that the time to failure depends on the block size, channel slope, and specific discharge. The result revealed that the slope of the channel has a significant effect on the characteristic time to failure. In addition, the larger block sizes postponed the time to failure and also reduced the block erosion rate for a fixed longitudinal slope.

A relation between the time to failure and the bed shear stress, both normalized with the block size as geometric parameter, was proposed. However, the best results were obtained by normalizing the time to failure with the flow depth as geometric parameter.

An empirical relationship allows estimating the time to failure for the tests which remained stable. The results revealed that the rate of erosion, which is expressed by the number of eroded blocks, is kept limited until the failure occurs. The cumulative number of eroded blocks remains in a narrow band, independent of the block size.

This study serves to forecast the time to failure of compressed riprap used as river bank protection, in the range of applications corresponding to the experimental set-up described here. 


\section{Acknowledgements}

The authors thank Ben Plumb for the English revision of the manuscript. The authors acknowledge the work of the Editor and reviewers to improve this article.

\section{Funding}

The research project is financed by the Swiss Federal Office for the Environment (FOEN) under contract no. [A2111.0239/100019.PJ/J372-1192].

\section{Notation}

$D \quad=$ block size $(\mathrm{m})$

$\mathrm{F} \quad=$ Froude number $(-)$

$g \quad=$ gravity acceleration $\left(\mathrm{m} \mathrm{s}^{-2}\right)$

$h=$ flow depth (m)

$L \quad=$ generic length $(\mathrm{m})$

$n_{p}=$ porosity $(-)$

$q=$ unit discharge $\left(\mathrm{m}^{2} \mathrm{~s}^{-1}\right)$

$S=$ longitudinal channel slope $(-)$

$S_{B}=$ specific gravity of blocks (-)

$t=$ time $(\mathrm{min})$

$t_{f}=$ time to failure ( $\left.\mathrm{min}\right)$

$t^{*}=$ normalized time to failure $(-)$

$T_{D}^{*}=$ normalized time to failure characterizing block size $(-)$

$T_{h}^{*}=$ normalized time to failure characterizing flow depth (-)

$u_{*} \quad=$ shear velocity $\left(\mathrm{m} \mathrm{s}^{-1}\right)$

$V \quad=$ a generic flow velocity $\left(\mathrm{m} \mathrm{s}^{-1}\right)$

$v_{m}=$ mean velocity $\left(\mathrm{m} \mathrm{s}^{-1}\right)$

$W \quad=$ channel width $(\mathrm{m})$

$\rho \quad=$ water density $\left(\mathrm{kg} \mathrm{m}^{-3}\right)$

$\rho_{\mathrm{s}} \quad=$ riprap density $\left(\mathrm{kg} \mathrm{m}^{-3}\right)$

$\tau \quad=$ bed shear stress $(\mathrm{Pa})$

$\tau^{*}=$ dimensionless bed shear stress $(-)$

\section{References}

Abt, S. R., Thornton, C. I., Gallegos, H. A., \& Ullmann, C. M. (2008). Round-shaped riprap stabilization in overtopping flow. Journal of Hydraulic Engineering, 134(8), 10351041. doi:10.1061/(ASCE)0733-9429(2008)134:8(1035)

Blodgett, J. C., \& McConaughy, C. E. (1986a). Rock riprap design for protection of stream channels near highway structures: Volume 1-Hydraulic characteristics of open channels (Water-Resources Investigations Report 86-4127). Sacramento, CA: US Geological Survey.

Blodgett, J. C., \& McConaughy, C. E. (1986b). Rock riprap design for protection of stream channels near highway structures: Volume 2 - Evaluation of riprap design procedures
(Water-Resources Investigations Report 86-4128). Sacramento, CA: US Geological Survey.

Brown, S. A., \& Clyde, E. S. (1989). Design of the riprap revetment. Hydraulic Engineering Circular 11. McLean, VA: Federal Highway Administration.

De Almeida, G. A. M., \& Martin-Vide, J. P. (2009). Riprap stability: Transverse and longitudinal versus continues protections. Journal of Hydraulic Engineering, 135(6), 447-456. doi:10.1061/(ASCE)HY.1943-7900.0000031

Escarameia, M., \& May, R. W. P. (1992). Channel protection downstream of structures (Rep. SR 313). Wallingford: HR Wallingford.

Froehlich, D. C. (2011). Mass angle of repose of open-graded rock riprap. Journal of Irrigation and Drainage Engineering, 137(7), $454-461$.

Froehlich, D. C. (2013). Sizing loose rock riprap to protect stream bank. River Research and Application, 29(2), 219235. doi:10.1002/rra.1587

Froehlich, D. C., \& Benson, C. A. (1996). Sizing dumped rock riprap. Journal of Hydraulic Engineering, 122(7), 389-396. doi:10.1061/(ASCE)0733-9429(1996)122:7(389)

Grace, J. L. Jr., Calhoun, C. C. Jr., \& Brown, D. N. (1973). Drainage and erosion control facilities: Field performance investigation. Vicksburg, MS: US Army Engineer Waterways Experiment Station.

Jafarnejad, M. (2016). Time dependent failure analysis of large block size riprap as bank protection in mountain rivers. Thesis 6803, Communication $\mathrm{N}^{\circ} 62 \mathrm{du}$ Laboratoire de constructions hydrauliques, A. Schleiss (ed.), Ecole Polytechnique Fédérale de Lausanne, Lausanne, Switzerland. doi:10.5075/epfl-lchcomm-62

Jafarnejad, M., Franca, M., Pfister, M., \& Schleiss, A. J. (2014). Effect of compressed riprap thickness on the stability of river banks. In A. J. Schleiss, G. de Cesare, M. J. Franca, \& M. Pfister (Eds.), River flow 2014: international conference on fluvial hydraulics (pp. 2069-2074). London: Taylor \& Francis.

Jafarnejad, M., Pfister, M., \& Schleiss, A. J. (2012). Failure risk analysis of riverbank ripraps with Monte Carlo Simulation. In R. Murillo Muñoz (Ed.), River flow 2012: volume 1 (pp. 1325-1330). London: Taylor \& Francis.

Lagasse, P. F., Clopper, P. E., Zevenbergen, L. W., \& Ruff, J. F. (2006). Riprap design criteria, recommended specifications, and quality control. Washington, DC: National Cooperative Highway Research Program.

Li, R. M., Simons, D. B., Blinco, P. H., \& Samad, M. A. (1976). Probabilistic approach to design of riprap riverbank protection. Rivers 76th Symposium on Inland Waterways for Navigation, Flood Control, and Water Diversions, Vol. I: 1572-1591. ASCE, Fort Collins, CO.

Maynord, S., \& Neill, C. (2008). Riprap design (Appendix B). In H. M. García (Ed.), Sedimentation engineering (pp. 1037-1056). Reston, VA: ASCE. doi:10.1061/9780784 408148 
Maynord, S. T., Ruff, J. F., \& Abt, S. R. (1989). Riprap design. Journal of Hydraulic Engineering, 115(7), 937-949. doi:10.1061/(ASCE)0733-9429(1989)115: $7(937)$

Permanent International Association of Navigation Congress (PIANC). (1987). Risk consideration when determining bank protection requirements. Report of Permanent Technical Committee 1, Supplement to Bulletin 58. Brussels.

Recking, A., \& Pitlick, J. (2013). Shields versus Isbash. Journal of Hydraulic Engineering, 139(1), 51-54. doi:10.1061/ (ASCE)HY.1943-7900.0000647

Schleiss, A. J. (1998). Bemessung und Gestaltung von Blockwürfen an Gebirgsflüssen. [Design and landscape integration of riprapin mountain rivers]. Interpraevent. Villach. Tagungspublikation, Band, 2, 351-360.

Simarro, G., Civeira, S., \& Cardoso, A. H. (2012). Influence of riprap apron shape on spillthrough abutments. Journal of Hydraulic Research, 50(1), 138-141. doi:10.1080/00221686. 2011.650422

Stevens, M. A., Simons, D. B., \& Lewis, G. L. (1976). Safety factors for riprap protection. Journal of the Hydraulics Division, 102(HY5), 637-655.
Stevens, M. A., Simons, D. B., \& Richardson, E. V. (1984). Riprap stability analysis. Transportation Research Board, Transportation Research Record, 2: 209-216.

Straub, L. G. (1953). Dredge fills closure of Missouri River at Fort Randall. In L. A. Johnson (Ed.), Proceedings: Minnesota International hydraulics convention (pp. 61-75). Minneapolis, MN: WM.C. Brown.

Townson, J. M. (1988). The simulated motion of a loose revetment block. Journal of Hydraulic Research, 26(2): 225-242. doi:10.1080/00221688809499226

Ulrich, T. (1987). Stability of rock protection on slopes. Journal of Hydraulic Engineering, 113(7), 879-891. doi:10.1061/ (ASCE)0733-9429(1987)113:7(879)

US Army Corps of Engineers (USACE). (1994). Hydraulic design offlood control channels. EM 1110-2-1601. Washington, DC: US Government Printing Office.

Wittler, R. J., \& Abt, S. R. (1988). Riprap design by modified Safety factor method. In S. R. Abt \& J. Gessler (Eds.), Proceeding of national conference on hydraulic engineering (pp. 143-148). Colorado Springs, CO: ASCE.

Yalin, M. S. (1977). Mechanics of sediment transport. Oxford: Pergamon Press. 